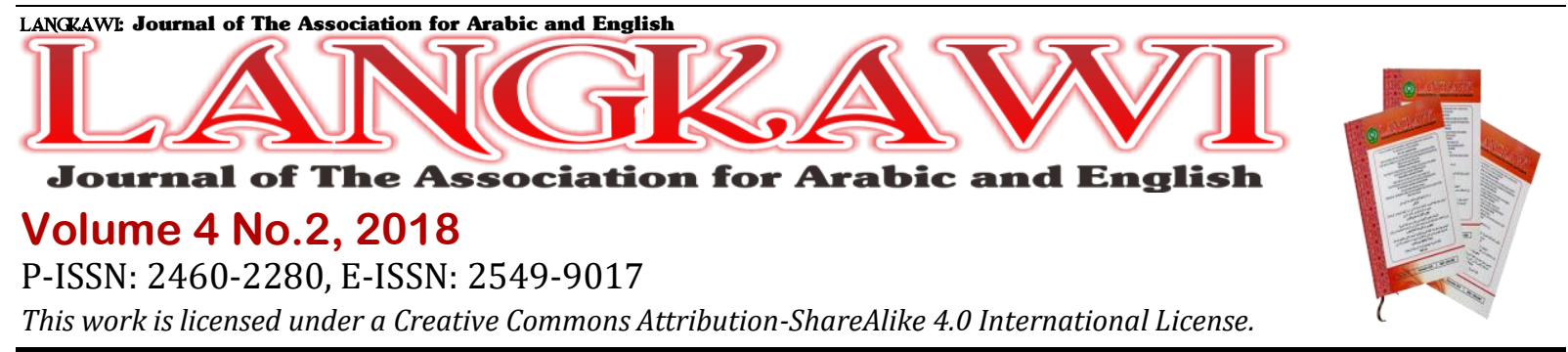

\title{
Students' Writing Errors and What Lies Beyond Them
}

\section{Fahmy Imaniar}

Universitas Negeri Surabaya, Indonesia.E-mail: fahmyimaniar16070835008@mhs.unesa.ac.id

ARTICLE INFO
Keywords:
Writing; Writing Errors;
Error Analysis;
Interlingual; Intralingual
How to cite:
Imaniar, F., (2018).
Students' Writing Errors
and What Lies Beyond
Them, 4(2), 71-83.
DoI:
http://dx.doi.org/10.31332/
lkw.v4i2

\begin{abstract}
Writing in the second language is onerous that leads learners to make errors in their performance. Fortunately, the view of error has changed into a way of understanding second language acquisition and its practice. Error analysis is an approach of SLA to learn the errors made by the second language learners. However, knowing the errors made is not enough; therefore, it is important to see the factors beyond the errors. This present study aims at identifying what writing errors the learners make and what the most common error occurs are. Furthermore, this study explored what factor lies beyond those errors. Through mixed method design as well as Error Analysis (EA) approach, this study was conducted in one learning course in Sidoarjo, East Java, Indonesia. The data were collected through content analysis and interview, in which writing task and interview guideline were used as the instruments. This study revealed that omission was the type of error mostly made. Furthermore, intralingual and interlingual factors were the ones beyond the errors. It is expected that this study will contribute to the knowledge and practice on the fields of not only Second Language Acquisition (SLA) but also English Language Teaching (ELT) involving teachers and students.
\end{abstract}

\section{Introduction}

From the former time up to today, there is no doubt that writing becomes a scope in which one's second language can be best performed. The aspects of the second language gained from the other English receptive skills - i.e., listening and reading, that have been acquired need to be elicited and writing is the area learners are possible to do so. Harmer (2012) states that writing is undoubtedly able to help students in joining all the knowledge of the language that they have been acquired. In other words, it becomes the result of showing one's overall skills in English. However, learners often find it difficult to write a specific composition which is not their first language even though they have acquired knowledge of the second language that they are learning. Writing requires them to use English words that arranged into sentences and paragraphs by following specific grammatical rules; therefore it is considered as the most difficult one compared to the others (Hyland, 2003; Cahyono\&Widiati, 2011). Hence, as the consequences, learners tend to make errors in their writing due to the issue.

At first, all errors that learners made considered as deviations that they should not happen (Gunawan, 2015). It suggested that the writers cannot perform the 
language that has been acquired (Fauziati, 2003). Although it has justification, the view of errors in second language learning has already changed. Errors are not always bad things that need to be wiped out, yet they performed crucial aspects of the second language learning process as stated by Corder $(1967,1981)$. They give information related to the learner's process of learning a second language. Therefore, to study the learner's second language systems of acquisition, analyzing the errors that learners made is one fruitful way to do it.

In analyzing the issue above related to students' errors, an approach of SLA (Second Language Acquisition) called Error Analysis (EA) is needed. Error Analysis concerns on the learners' creative skill in constructing the second language which is done by describing and analyzing their errors in producing or employing L2 (SavilleTroike, 2012:40). It is also seen as a study of second language learners' morpheme development (Krashen, 1997 cited in Lightbown and Spada, 2006). Though EA, errors are seen as a way to see the learner's mind as they reflect the point of the learner's second language development and give chances to interpret the meaning of those errors as well as, later on, find a way to reduce them. Once the errors and the causes are revealed, it will be possible to decide what solution or treatment to do and also emphasize the alleviation of errors for the next writing (Al-Mohanna, 2014: 79). Accordingly, EA is a useful approach to do in dealing with students' errors in writing English as their second language.

Analyzing errors needs a particular classification. According to Dulay et al. (1982), there are four categories of classification in analyzing errors, i.e., linguistic category classification, surface strategy taxonomy, comparative taxonomy, and communicative effect taxonomy. Among those ways of classifying errors, surface strategy taxonomy is a preferred way to know the types of errors the students make as well as leading them to unlock the factors beyond those errors.

Formerly, there have been several studies employing EA in analyzing second language learners' errors in writing carried out (Mungungu, 2010; Herlinawati, 2011; Wahyudi, 2012). However, none of those studies analyze the learners' errors according to surface strategy taxonomy and investigates the reasons beyond those revealed errors. Herlinawati (2011) employed surface strategy taxonomy to do the error analysis, but she stopped at revealing they type of errors and the most common errors only. Meanwhile, Mungungu (2010) and Wahyudi (2012) used a linguistic category to classify the errors revealed. Similar to Herlinawati (2011, they also did not try to explore what lies beyond those errors. Therefore, this present study is conducted to unlock the area beyond the errors that learners made in their writing. It involves Indonesian Junior high school studies English in a learning course as the participants.

\subsection{Literature Review}

Through this literature review, some information is given to assist readers in having a better understanding of what this paper is discussing. Some concept, theories, and related studies dealing with Second Language writing, errors, and Error Analysis are included and presented in the following sections.

a. Second Language Writing

Bridges et al. (1984) defined writing as the phase in where a basic draft of a composition produced by the particular writer. Expressing the feelings and 
presenting the language other than the first language, are the essential things for the students even though writing is considered more difficult compared to other language skills. The scope of writing is broad depending on the curriculum used as well as the level of the learners.

Indonesia used Genre-Based approach (GBA) in ELT teaching practice for a secondary school, including junior high school (Emilia, 2011). It means that text genres or text types become the basis of all language skills learned, including writing. There are several types of text becoming the basis of students' writing activities, i.e., procedure text, descriptive text, narrative text, and so on. Descriptive text is one type of genre-based writing text that underlays the writer's objective in describing a specific subject. The subject in descriptive writing can be a person, a thing, an animal, or even a place. Regarding language features used for writing, descriptive also deals with the use of simple present tense as the basic grammatical rules employed.

\section{b. Errors}

Making errors is okay and even considered necessary in the process of language learning. Error analysis is a linguistic approach to Second Language Acquisition (SLA) which came up after the previous approach, Contrastive Analysis (Saville-Troike, 2006:37). The notion of error analysis was firstly proposed by Corder (1967; 1981). He stated that the existence of errors give evidence that one's second language is being developed and a sign showing learner's exploration of their L2. Moreover, errors are part of learning that opens up the possibility to go to the learner's mind.

\section{c. Error Analysis}

Error analysis is seen as an approach which aims at describing and explaining the deviations or errors that are produced in the learner's language. In doing error analysis, there is a procedure which is considered necessary to follow. The method of error analysis consists of a collection of samples, identification of errors, description of errors, explanation of errors, and evaluation of errors (Ellis, 1994 cited in SevilleTroike, 2006). Collection of samples deal with the phase of determining the pattern of error found. After that, there is a need to identify the error to make sure that it is errors, not mistakes. Then, the errors are describing through the process of classification and categorization. In the next step, the errors are explained regarding its cause, whether it is interlingual or intralingual. The last one is evaluating the errors by stating how significant the errors are and whether they are serious errors or not.

Corder (1981:10-11) points out some significances of doing error analysis. For teachers, error analysis gives them information on how far the learner has learned or the progress of his/her learning of L2 and what remains to learn. Meanwhile, for researchers, error analysis can provide evidence related to how language is acquired or learnt. Error analysis does not give significance for only teachers and researchers but also the learners or the students. For them, error analysis has a role as a device that can be used to learn and develop their target language.

\section{d. Types of Errors}

Before classifying the types of errors, it is important to underline that errors are different from mistakes. According to Corder (1981: 10), errors deal with 
deviances which are caused by lack of competence, while mistakes are regarded as the performance of errors which are considered not significant. Errors are the result of learners' transitional competence, while mistakes are the result of an external factor to the competence of the speaker.

There are a lot of types of errors depending on the classification way used. Dulay et al. (1982) point out four significant classifications of errors. The first one is linguistic category classification which deals with the location of errors in the overall system of the target language covering linguistic levels, word classes, and also grammar constructions (p. 147-150). The second one is surface strategy taxonomy which deals with the way surface structure changed through the errors (p. 150). This classification covers omission, addition, misformation, and also misordering. Comparative taxonomy is another classification of errors dealing with "the comparisons between the structure of L2 errors and certain other types of constructions" (p. 163). It covers developmental or intralingual errors and interlingual errors. The last classification is communicative effect taxonomy which takes a view from the reader or listener whose perspective on the effect of errors is emphasized.

In written text, the second classification proposed by Dulay et al. (1982), surface strategy taxonomy, is appropriate to be used since it is more suitable to apply for written errors than spoken ones even though it can. There are four types of errors based on taxonomy surface strategy, most of which have some sub-types. They are an omission, addition, misformation, and misordering.

An omission is indicated by "the absence of an item that must appear in a well-formed utterance" (Dulay et al., 1982:154). The omission of grammatical morphemes is more frequent than omission regarding content words (p. 155). To break down this type of error, the sub-types may be referred to grammatical morphemes occurred (omission on verbs, the omission of adverbs, and so on)

The addition is indicated by "the presence of an item which must not appear in well-formed utterance" which is the opposite of omission (Dulay et al., 1982: 156). There are three sub-types of addition, i.e., double markings, regularization, and simple addition. Double markings occur because of "the failure to delete certain items which are required in some linguistic constructions" (p. 156). Regularization deals with the influence of common pattern of addition which is usually and commonly given to some linguistic items with the same type. Regularization is also known as overgeneralization. Simple addition deals with errors also which do not belong to double markings or regularization.

Misinformation is indicated by the form of structure or morpheme which is considered wrong (Dulay et al., 1982:158). There are some subtypes of misinformation, i.e., regularization errors, archi-forms, and alternating forms. Regularization errors here deal with the influence of the common form used by some linguistic items with the same type. It is different from regularization also for some extents, although it is also commonly called overgeneralization. Archi-forms deal with the selected form which represents the other members of the class (p. 160). Meanwhile, alternating forms deals with "free alternation of various members of a class with each other" (p. 161). 
Misordering is indicated by "the incorrect placement of a morpheme or group morphemes in an utterance" (Dulay et al., 1982: 162). Misordering has no specific sub-types since it is clear that if it deals with placement, then it belongs to this type of error.

\section{e. Potential Factors of Errors}

In analyzing errors, revealing the factors or reasons why the errors are made is essential to understand second language acquisition (SLA) process. Interlingual and Intralingual factors are the most influential factors beyond the errors that learners made (Saville-Troike, 2012:42). Interlingual factors are caused by the negative transfer from L1 into L2. In other words, the learners' first language interferes their use of the second language. Meanwhile, intralingual factors deal with the learners' knowledge of second language rules, and it can be developed; therefore, the errors caused by these factors are regarded as developmental errors.

\section{f. Related Studies}

Mungungu, (2010) investigates general errors that non-English speakers made based on linguistic category classification. The corpus-based study found that the most common category of errors made by the participants, university students, were spelling, articles, prepositions, and tenses. However, Mungungu limited her study only to reveal the types of errors and the most common errors made by the students.

Unlike Mungungu, Herlinawati (2011) analyzed the errors based on surface strategy taxonomy, and the subjects were secondary school students. Narrative text becomes the genre that the students' writing output underlaid. She had questioned the factors causing the errors, yet the question is not answered. She just calculated and described the errors that she found in the learners' composition.

Wahyudi (2012) conducted a study of error analysis focusing on the subjectverb agreement in the English department students' writing composition. He used surface strategy taxonomy to classify the errors and found that there is 60 incorrect subject-verb agreement which many of the errors belonged to misinformation. He discussed the source of errors interpreted from the subject-verb agreement errors, but he did not explore the reasons by checking to the learners' explanation.

Regarding to the former studies (Mungungu, 2010; Herlinawati, 2011, Wahyudi, 2012), this present study was carried out to not only reveal the types of errors that second language learners made in writing and the most common error occurred, but also dug up the factors beyond those errors, not only from the errors but also exploring information from the ones who did it.

\section{Method}

This study used a mixed method involving both quantitative and qualitative research design. The quantitative research design was employed to reveal what errors that the students made and found the most common one. Meanwhile, a qualitative method was used to explore the factors which caused the errors that the students made. The quantitative data were obtained through content analysis employing error analysis (EA) approach as proposed by Ellis (1994, cited in SavilleTroike, 2006), while the qualitative data were done through an interview with the students chosen as the samples.

The study was carried out in a class of one learning course in Sidoarjo, East 
Java, Indonesia. There were five classes for Junior High School students actually, but only one particular class was chosen to be the setting to conduct the study. The subjects were the ninth-grade students attending the class. There were 12 students in the class consisting of 7 female students and five male students.

The data in this research were obtained from the students' writing products on descriptive text. The focus was on the errors committed by the students in their written composition. The data were analyzed by searching and classifying the errors found into the categories. The process of the whole error analysis follows Ellis' (1994, cited in Saville-Troike, 2006) model of analysis which covers collection of samples, identification of errors, description of errors, explanation of errors, and evaluation of errors. The description of errors applied the classification in surface strategy taxonomy proposed by Dulay et al. (1982). Therefore, the analysis would cover some types of errors including omission, addition, misformation, and misordering.

To find out the most frequent errors occurred in students' composition, the data of the errors were calculated based on the classification of surface strategy taxonomy. A simple formula as follows was used so that the frequency can be presented in percentage.

$$
x=\frac{n}{\sum n} \times 100
$$

$x=$ the percentage of an error type

$n \quad=$ the number of the particular type errors found

$\sum n \quad=$ the total number of all errors

In the finding, some data which represented the main errors would be presented. It would not present all the errors found since the data were plenty. The analysis was done by identifying the errors and their types and also comparing them to the proper forms reconstructed from the forms considered as errors.

Also, the data from the interview were transcribed and analyzed through the Interactive Model proposed by Miles, Huberman, and Saldana (2014). The process involves data reduction, data display, and also conclusion drawing. The interview was semi-structured one which enabled the researcher to get more data from the subject. The questions focused on the errors that the matter had made.

\section{Findings and Discussion}

From the data analysis, there were 69 errors found in 12 students' composition. The errors found were classified into four types based on surface strategy taxonomy classification pointed out by Dulay et al. (1982), i.e., omission errors, addition errors, misformation errors, and misordering errors.

From the result of the analysis, it was found out that the most frequent errors occurred in students' composition was an omission. There were $40.58 \%$ omission errors found in the result of the analysis. Twenty-eight out of 69 errors belonged to omission errors.

Among those four errors, addition and misordering errors were the most infrequent ones occurred in students' writing composition of the descriptive text. Each of them occupied $10.14 \%$ of all errors occurred. Meanwhile, the other 39.13\% 
errors were misformation errors which became a type of error with the most significant number after omission. The difference between them was not so far.

Table 3.1 The Result of Errors Analysis Based on Surface Strategy Classification

\begin{tabular}{|c|c|c|c|c|c|c|c|c|c|c|c|}
\hline \multirow{3}{*}{\multicolumn{2}{|c|}{ NO NAME }} & \multirow{2}{*}{\multicolumn{4}{|c|}{ OMISSION }} & \multirow{2}{*}{\multicolumn{4}{|c|}{$\begin{array}{l}\text { ADDITIO MISFORMATION } \\
\mathrm{N}\end{array}$}} & \multicolumn{2}{|c|}{ MISORDERI TOT } \\
\hline & & & & & & & & & & \multirow{2}{*}{ NG } & \multirow[t]{2}{*}{ AL } \\
\hline & & \multirow[t]{2}{*}{$\begin{array}{l}\text { Aux } \\
\text { verb }\end{array}$} & \multirow[t]{2}{*}{$\begin{array}{l}\text { Pluralit } \\
\text { y }\end{array}$} & Article & $\begin{array}{l}\text { Other } \\
\text { omission } \\
\text { s }\end{array}$ & $\begin{array}{l}\text { Simple } \\
\text { Addition }\end{array}$ & \multicolumn{2}{|c|}{$\begin{array}{l}\text { Regula Archi- } \\
\text { rizatio forms } \\
n\end{array}$} & $\begin{array}{l}\text { Alternati } \\
\text { ng form }\end{array}$ & & \\
\hline 1 & YOS & & & & 3 & 1 & & & & 1 & 5 \\
\hline 2 & FER & 2 & 2 & 1 & & 1 & & & & & 6 \\
\hline 3 & ADI & 1 & & & 1 & 1 & & 4 & & 2 & 9 \\
\hline 4 & PUT & & & 1 & 1 & & & 1 & 1 & 2 & 6 \\
\hline 5 & ISR & & & & 2 & & & 1 & & & 3 \\
\hline 6 & ILM & & & & 1 & 1 & & 1 & & & 3 \\
\hline 7 & ZAL & & 1 & 1 & & & 1 & 2 & & 1 & 6 \\
\hline 8 & AMA & 1 & & 1 & 1 & & & & 3 & & 6 \\
\hline 9 & QOF & & & & 1 & 2 & 1 & & & 1 & 5 \\
\hline 10 & ASA & 1 & & 2 & 2 & 1 & & & 1 & & 7 \\
\hline 11 & SAN & & & & 1 & & & 2 & 4 & & 7 \\
\hline 12 & ERI & & & & 1 & & & & 5 & & 6 \\
\hline $\mathrm{TO}^{-}$ & TAL & 5 & 3 & 6 & 14 & 7 & 2 & 11 & 14 & 7 & 69 \\
\hline $\mathrm{TO}^{\prime}$ & TAL 2 & 28 & & & & 7 & 27 & & & 7 & 69 \\
\hline $\begin{array}{l}\text { PEI } \\
\text { GE }\end{array}$ & RCENTA & 40.58 & & & & 10.14 & 39.13 & & & 10.14 & 100 \\
\hline
\end{tabular}

\subsection{Types of Errors Found}

\section{Omission}

The result of the analysis shows that 28 out of 69 errors are an omission. The errors occurred when the students omitted specific item that necessarily existed in their sentence, most of which influenced the grammatical consideration of the composition. The omission errors found includes $17.86 \%$ of auxiliary verb omission errors, $10.71 \%$ of plurality form omission errors, $21.43 \%$ of article omission errors, and $50 \%$ of other kinds of omission errors. The examples of omission errors found are:

(a) He good with fans

(b) He is Juventus football club 
Those two examples are incorrect regarding good sentence construction. In example (a), the student omitted the auxiliary verb that should appear after the subject. It violates the grammar rules, moreover. In example (b), the student omitted the proposition of the sentence. If those two examples can be constructed then they will become the following:

(a) He is good with fans

(b) He is from Juventus football club

\section{Addition}

From the result of the study, it is found that $10.14 \%$ of all errors were addition errors. It occurred because the students add a specific item that should not exist in their sentences. There is only one kind of addition errors, simple addition. The example of addition errors found is:

He is very smart and famous and strong

From the example above, it can be seen that the student used too many conjunctions by adding and between smart and famous. If there are more than two words, then the conjunction and is necessary only before the very last word. The following is the revised form of the example.

He is very smart, famous, and strong

\section{Misformation}

The result of the analysis shows that misformation type of errors had the second most significant number of errors. There were 27 out of 69 errors classified into misformation errors. The errors occurred due to the wrong structure. The misformation errors found in the result of this study includes $7.41 \%$ of regularization errors, $40.74 \%$ of archi-form errors, and $51.85 \%$ of alternating forms errors. The examples of addition errors found are:

(a) He is a woman

(b) He has pointed nose

From those two examples, it can be seen clearly that the students used the wrong structure. In example (a), the woman is identically female that the correct pronoun is not he but she. In example (b), the use of the verb is incorrect. For pronouns he, she, it, the sentence should use has instead of have. Have is used for pronouns I, you, they, and we. Therefore, the revised form can be like the following:

(a) She is a woman

(b) He has pointed nose

\section{Misordering}

The result shows that $10.14 \%$ of all types of errors were misordering errors. The number of percentages was the same with addition errors that there were only 3 out of 69 errors belonged to each of the two types of errors. The misordering errors happened due to the wrong placement of items in the students' sentence structure. The example of addition errors found is:

Suarez has eyes blue 
The example above points out that the student put the last two words in the wrong order. The adjective should come up before the noun it modifies. If the example is reconstructed, it will be:

\section{Suarez has blue eyes}

\subsection{The Factors Causing the Errors}

Through the interview, it was found that the students lacked grammar knowledge in the second language. Some of them just have known the right grammatical rules after it is explained during the interview. The following is part of the interview discussing the sentence written 'He has pointed nose.'

"Why is it incorrect, Miss? The English term of owning something is 'have, ' isn't it?"

Some explanation was then inserted in the interview in which overall, showed that intralingual factors were the ones existing beyond the errors. Most of them stated that they did not know the correct form of the sentence that they had made. Some others had already known it, but they forgot to employ it in their writing.

Although some errors were caused by intralingual factors, there were several other errors which were caused by interlingual factors. For example, the sentence is written 'Suarez has eyes blue.' The misordering error happened in the sentence was not because of the lack of grammar knowledge of the second language, but it was more on the interlingual factors. In his L1, Indonesian, the noun comes first before the adjective, yet in L2, the order is vice versa. The following is the statement of the students writing the sentence.

"In Indonesia, we have eyes which are blue, so blue eyes, Miss. Why is in English the order is different?"

The respond and the question of the student led to their cognitive thinking which his L1 did affect his production of L2. Although the amount was not as much as interlingual factors, the interpretation of this issue could be broader.

\subsection{Discussion on the Revealed Errors}

From the results of the study, it is shown that the most frequent errors are an omission. This result supports what has been found by Yuliani (2015:15) in her study in which the most common type of error occurs was an omission. From the representative example, it can be seen that the students omit items which are necessary to exist. They tend to omit items which are related to the nature of English mastery elements, particularly grammar. It is in line with the statement of Dulay et al. (1982:155) that students are more frequently to omit grammatical structure items than to omit content words. They tend to lack knowledge of the notion that some particular items should exist to construct it as a well-formed sentence.

In contrast to the result of omission, addition errors made up only $10.41 \%$ of the whole errors. Moreover, there is only one single type of addition found in the study, simple addition. It implies that the students had already the basic concept or rule of a certain structure, yet they are not aware that put certain items that should not exist. It supports Dulay et al.'s (1892) stating that addition errors are good characteristics which indicate that the students have been acquired some basic rules, but not yet for the refinements. From the examples given in the finding, it can be 
implied that the sentence the student made is highly understandable in meaning, yet it is considered incorrect.

The second most frequent errors are misformation which is indicated by the existence of items that should not exist in a well-formed sentence. The difference between the result of omission errors and misformation errors was only $1.45 \%$ which means that this error is extremely needed the teacher's attention. Alternating forms and archi-form have the most significant number of all misformation errors. Relating to the example given in the finding, it is good to know that the student knows what verb he/she had to use in applying simple present tense although they were still confused in distinguishing between the use of have and has in correlation to the type of pronouns used. The other example indicates an error in the alternating form in which he fails to use the correct form of pronoun representing a female figure. According to Dulay et al. (1982:161), in the case of pronouns, alternating form errors include the wrong use of masculine for feminine or feminine for masculine. It is in line with what happened to the students. Therefore, it is necessary to emphasize the concept of word classes and differentiate the use of their members.

The last type of error found is misordering which is related to the wrong placement of some particular items in a sentence. The result is exactly the same with addition. The example of misordering given in the finding implies that the student's L1 affects his/her English performance in writing. In Indonesia, the sentence could be written as Suarez memiliki mata berwarna biru or Suarez bermata biru that shows the eyes comes first before the blue. However, in English the concept is different. Therefore, the student's error was caused by his/her interlanguage which shows that the student's English language performance is influenced by his/her native language, Indonesian.

The result of the study motivates an argument dealing with surface strategy taxonomy. Although Dulay et al. (1982) emphasize the classification of errors in speech, this study points out that it can significantly be used for analyzing and classifying errors in the written text. To know the type of errors and take an interpretation from them, surface strategy taxonomy is appropriate.

From the whole result of the study, it can be interpreted that interlingual factors contribute to the students' errors occurred in their writing, yet intralingual factors are still the dominant one. Interlingual is the factor of errors resulting from negative transfer from students' L1, while intralingual is the factor of errors dealing with the inside of the target language or L2 (Saville-Troike, 2006:39). The use of the L1, Bahasa Indonesia influence the way the students construct sentences (Afifuddin, 2016:136). Then, it leads to the errors production in students' language performances. Besides, relating to intralingual factors of errors, Mustafa et al. (2016:49) states that the complexity of grammatical rules in English or incomplete learning and mastery of the rules which lead their errors to occur.

Furthermore, Ciesielkiewicz (2015:133) points out that the students' difficulty dealing with English grammar rules is much more complex compared to the spelling or constructing the well-formed word. Both statements support Richard's (1973:6) statement that intralingual factors reflect the difficulty of learning as well as give information on what rules in the target language that is still low-mastered. Therefore, the errors can be seen as a good point showing what students had learned. It 
becomes a reference for teachers on what should teach and emphasize to help the students develop their English as well as reducing the errors.

Through the result of the study, the meaning of the existence of errors and conducting error analysis is derived. Making errors is important, and it should not be seen as only weaknesses of the students. Jabeen et al. (2015) show that making errors is important for students in the process of language learning. Besides, errors analysis is also important since it provides a different view about the process of language learning. Moreover, Darus (2009:493), whose study supports the previous argument, states that error analysis emerges insights that is beneficial for teachers due to its information related to the students' learning problems and preparation of future teaching. Moreover, what is proposed by Corder (1981) related to the significance of errors and the notion of error analysis is significant to the pedagogical aspect as well as for second language acquisition of the students

\section{Conclusion}

Based on the result of the analysis and the discussion provided in previous chapters, it can be concluded that the most frequent errors occurred in students are omission errors. The parts of language having omission errors are considered as an important point to pay attention. Misformation errors also considered frequent since the difference is no more than 2 percent. In general, the frequency of errors covers the four types of errors based on surface strategy taxonomy. The factors of students' errors include both intralingual and interlingual factors, but intralingual factors are the dominant one. It shows that limited knowledge of the other skills will affect a limited knowledge of students' writing. In other words, beyond those errors are the

Referring to the result of the study, there are some suggestions to offer. Firstly, the students should learn more about their ways of constructing sentences including the use of some grammatical features so that they will improve their writing skills by reducing their common-made errors. Secondly, the teachers are expected to make use of the result of the error analysis in order helping students improve their writing skill and reducing their errors as well as constructing a plan what treatment and emphasizing they need to bring to the class. Lastly, since this study is limited to one single class only, further researchers are possible to expand the number of subjects to see whether what lies beyond the students' writing errors is the same or different with the one revealed in this study. Besides, further researchers are also expected to make use the finding of this study to conduct another research with a similar topic in different contexts and components - including the categorization of error analysis, so that it will give a contribution to the English language teaching as well as applied linguistics field.

\section{References}

Afifuddin. (2016). An Analysis of Students' Errors in Writing Descriptive Texts. English Education Journal, 7(1), 130-139.

Al-Mohanna, A. D. (2014). Errors in the Usage of Definite/Indefinite Articles among Saudi University-level Students. International Journal of Arts and Sciences, 7(3), 79-95. 
Bridges, C.W., Lunsford, R. F. (1984). Writing: Discovery Form and Meaning. California: Widworth Publishing Inc.

Cahyono, B.Y., Widiati, U. (2011). Teaching English as a Foreign Language. Malang: State University of Malang Press.

Corder, J.P. (1981). Error Analysis and Interlanguage. Oxford: Oxford University Press.

Ciesielkiewicz, M., Marquez, E. (2015). Error Analysis and Its Relevance to Teaching ESL Composition. International Journal of Linguistics, 7(5), 119-138.

Darus, S. (2009). Error Analysis of the Written English Essays of Secondary School Students in Malaysia: A Case Study. European Journal of Social Sciences, 8(3), 483-495.

Dulay, H.C., Burt, M.K., Krashen, S.D. (1982). Language Two. New Oxford: Oxford University Press.

Emilia, E. (2011). Pendekatan Genre-Based dalamPengajaran Bahasa Inggris: Petunjukuntuk Guru. Jakarta: Rizqi Press.

Fauziati, E. (2003). Interlanguage Errors in English Textbooks for Junior High School Students in Surakarta. TEFLIN Journal, 14(2), 179-192.

Gunawan, F. تحليل الأخطاء النحوية فى نرجمة كتاب نصائح العباد (الدراسة فى نقد الترجمة). (2015) (1) (1) Langkawi: Journal of The Association for Arabic and English, 1(1), 71-84.

Harmer, J. (2012). Essential: Teacher Knowledge. Harlow: Pearson Education Limited.

Herlinawati. (2011). Error Analysis in the Students Writing Narrative Paragraph at MTsNPajajaranPamulang. Published Thesis, Jakarta: State Islamic University SyarifHidayatullah.

Hyland, K. (2003). Second Language Writing. Cambridge: Cambridge University Press.

Jabeen, A., Kazemian, B., Mustafal, M. S. (2015). The Role of Error Analysis in Teaching and Learning of Second and Foreign Language. Education and Linguistic Research, 1(2), 52-61.

Lightbown, P.M. \&Spada, N. (2006). How Languages are Learned. Oxford: Oxford University Press

Miles, M.B., Huberman, A.M., \& Saldana, J. (2014) Qualitative Data Analysis: A Methods Sourcebook (3rd edition). Los Angeles: SAGE Publication, Inc.

Mungungu, S.S. (2010). Error Analysis: Investigating the Writing of ESL Namibian Learners. Published Thesis, Namibia: University of South Africa.

Mustafa, F., Kirana, M., Bahri Y., Syamsul. (2016). Errors in EFL Writing by Junior High Students in Indonesia. International Journal of Research Studies in Language Learning, 6(1), 38-52.

Richards, J.C., Sampson, G.C. (1973). The Study of Learner's English. In Jack C. Richards. Error Analysis: Perspectives on Second Language Acquisition. London: Longman. 
Saville-Troike, M. (2006). Introducing Second Language Acquisition. Cambridge: Cambridge University Press.

Saville-Troike, M. (2012). Introducing Second Language Acquisition (2 ${ }^{\text {nd }}$ Edition). Cambridge: Cambridge University Press.

Wahyudi, R. (2012). Error Analysis on Subject-verb Agreement: The Case of a University Student in Indonesia. Research on Humanities and Social Sciences, 2(4), 20-25.

Yuliani, S., Pudjobroto, A.H., Sarosa, T. (2015). An Error Analysis of Descriptive Text Written by Junior High School Students in Surakarta. JoLLIET. 2(1), 12-17. 